\title{
Perceptions, use and attitudes of pharmacy customers on complementary medicines and pharmacy practice
}

Lesley A Braun ${ }^{1,2^{*}}$, Evelin Tiralongo ${ }^{3}$, Jenny M Wilkinson ${ }^{4}$, Ondine Spitzer ${ }^{2}$, Michael Bailey ${ }^{6}$, Susan Poole ${ }^{5}$, Michael Dooley ${ }^{5}$

\begin{abstract}
Background: Complementary medicines (CMs) are popular amongst Australians and community pharmacy is a major supplier of these products. This study explores pharmacy customer use, attitudes and perceptions of complementary medicines, and their expectations of pharmacists as they relate to these products.

Methods: Pharmacy customers randomly selected from sixty large and small, metropolitan and rural pharmacies in three Australian states completed an anonymous, self administered questionnaire that had been pre-tested and validated.

Results: 1,121 customers participated (response rate 62\%). 72\% had used CMs within the previous 12 months, 61\% used prescription medicines daily and $43 \%$ had used both concomitantly. Multivitamins, fish oils, vitamin C, glucosamine and probiotics were the five most popular CMs. $72 \%$ of people using CMs rated their products as 'very effective' or 'effective enough'. CMs were as frequently used by customers aged 60 years or older as younger customers (69\% vs. 72\%) although the pattern of use shifted with older age.

Most customers (92\%) thought pharmacists should provide safety information about CMs, 90\% thought they should routinely check for interactions, $87 \%$ thought they should recommend effective CMs, 78\% thought CMs should be recorded in customer's medication profile and 58\% thought pharmacies stocking CMs should also employ a complementary medicine practitioner. Of those using CMs, 93\% thought it important for pharmacists to be knowledgeable about CMs and $48 \%$ felt their pharmacist provides useful information about CMs.

Conclusions: CMs are widely used by pharmacy customers of all ages who want pharmacists to be more involved in providing advice about these products.
\end{abstract}

\section{Background}

Herbal medicines, nutritional and dietary supplements, also known as complementary medicines (CMs), have become increasingly popular in the United States, United Kingdom, Canada and Australia, with self-medication making up the majority of use [1-5].

While it is difficult to provide exact data on the use of complementary medicine in Australia it is clear that a significant proportion (up to 75\%) of the Australian public have used complementary medicine in a number of different forms $[2,6,7]$. Data from the Australian

\footnotetext{
* Correspondence: I.braun@alfred.org.au

${ }^{1}$ Cardiothoracic Surgical Research Unit, Department of Surgery, Monash University, Alfred Hospital, Melbourne, Australia
}

Bureau of Statistics shows an $80 \%$ increase in people employed as CM practitioners in the 10 years to 2006; in the same time period the number of people visiting $\mathrm{CM}$ practitioners within a 2 week period rose from approximately 500,000 to 750,000 [8]. Together with data from a national survey which estimated that $69 \%$ of Australian adults used at least one CM product and/or visited a CM practitioner in the previous 12 months, there is little doubt about the impact of CMs in Australian health care [2].

Community pharmacy is one of the main suppliers of $\mathrm{CM}$ products in Australia and is the primary outlet for approximately $40 \%$ of the total money spent on this sector which has been estimated at between AU\$800
C Biomed Central 
million and at AU $\$ 1.86$ billion dollars annually [2,7]. Several studies have investigated the attitudes and opinions of pharmacists and pharmacy students towards the use of CMs [9-13] however the attitudes, use and expectations of Australian pharmacy customers have not yet been examined. This is important to investigate as the widespread use of CMs is likely to have raised pharmacy customer needs and expectations of pharmacists' responsibilities with respect to CMs.

Within the community pharmacy setting, pharmacists and pharmacy assistants are in a position to provide guidance about consumer purchases of over the counter medicines. Indeed, as primary care providers, pharmacists have a professional obligation to provide information and guidance to patients about the quality use of all medicines, which, according to the Australian National Medicines Policy, includes CMs [14].

The primary aims of this project were to investigate the perceptions, use and attitudes of pharmacy customers to CMs and explore their expectations of pharmacy practice. Secondary aims were to compare patterns of CM use between younger and older (over 60 years) pharmacy customers.

\section{Methods}

An anonymous, self-administered questionnaire was developed to collect data from pharmacy customers (Additional file 1; Pharmacy customer CAM survey). The questionnaire adopted and adapted questions from other surveys $[2,7,15,16]$ and included new questions relevant to the study. An advisory committee consisting of three pharmacists and a consumer advocate also informed survey development. The questionnaire was pre-tested using a convenience sample of 40 randomly selected pharmacy customers and then revised before wider utilisation.

The survey consisted of 32 core questions which collected demographic, behavioural, health and attitudinal information. An additional 16 questions were asked of customers who reported using CMs. These questions focussed specifically on issues relating to CMs including which products were used, purchase locations, product effectiveness and attitudes to pharmacy practice as it currently relates to CMs. Response options varied depending on the type of question asked and included multiple choice, open-ended free text and Likert-scaled responses.

Three project sites were selected to provide information from 60 pharmacies located in metropolitan and regional areas of Australia. Melbourne (Victoria) and the Gold Coast (Queensland) were the metropolitan sites; Wagga Wagga (New South Wales) was the regional site. These locations were selected due to convenience for recruitment due to proximity to the investigators academic location. A representative population sample of 1000 customers was targeted based on approximately $50 \%$ expected to be using CMs.

Pharmacy sites used for customer data collection were randomly chosen using the pharmacy listing in a national telephone directory. Pharmacy managers were contacted and those that agreed for their site to be involved in the data collection phase were visited by a dedicated research assistant who randomly selected pharmacy customers for recruitment as they exited the stores. Customers were then approached by a research assistant in the pharmacy and asked if they would like to participate in a survey. Customers filled out the surveys on site before leaving the pharmacy.

All data were entered into an electronic version of the survey which was available through SurveyMonkey ${ }^{\mathrm{mm}}$, an on-line survey tool. Ethics approval was obtained from the Alfred and Monash Human Research Ethics Committee, and subsequently from Charles Sturt and Griffith University.

\section{Data analysis}

Descriptive and inferential statistics were calculated using SAS version 9.1 (SAS Institute Inc., Cary, NC, USA). Differences in proportions between groups were compared using chi-square tests for independent proportions or Fishers Exact tests where numbers were small. Continuous, normally distributed variables were compared using Student's t-test and reported as means (standard deviations), while non-normally distributed variables were compared using Wilcoxon Rank Sum tests and reported as medians (interquartile range). To reduce the chance of type I errors, a reduced p-value of 0.05 was considered to be statistically significant.

\section{Results}

A total of 1,121 pharmacy customers completed questionnaires (response rate 62\%), of which $65 \%(n=728)$ were from metropolitan Melbourne, 27\% $(n=307)$ from the Gold Coast region and $8 \%(n=86)$ from Wagga Wagga. Data were not collected on patient who declined to be involved. Of the 54 pharmacies that were involved, there were 30 from Melbourne, 16 from the Gold Coast and 8 from Wagga Wagga. More women participated in the survey than men ( $74 \%$ vs. $25 \%$ ) and participants ranged in age from 18 years to over 70 years with a broad range in between. Further demographic and baseline data are presented in Table 1.

\section{Self reported health of customers}

Nearly half (47\%) of participants reported their health as good, $36 \%$ as very good and $11 \%$ as excellent, with $5 \%$ reporting it as poor. Hypertension was reported by $24 \%$ 
Table 1 Demographic data of pharmacy customers

\begin{tabular}{|c|c|c|}
\hline & & $\mathrm{N}(\%)^{*}$ \\
\hline \multirow[t]{4}{*}{ Gender } & Male & $275(25)$ \\
\hline & Female & $805(74)$ \\
\hline & Not reported & $41(4)$ \\
\hline & Total number of respondents & $\begin{array}{l}1121 \\
(100)\end{array}$ \\
\hline \multirow{8}{*}{$\begin{array}{l}\text { Highest level of education } \\
\text { attained }\end{array}$} & Did not go to school & $6(0.5)$ \\
\hline & Secondary education & $343(31)$ \\
\hline & Certificate level & $218(20)$ \\
\hline & $\begin{array}{l}\text { Diploma and advanced } \\
\text { diploma level }\end{array}$ & $137(13)$ \\
\hline & Bachelor degree & $187(17)$ \\
\hline & Graduate diploma or certificate & $67(6)$ \\
\hline & Postgraduate degree & $110(10)$ \\
\hline & Not reported & $24(2)$ \\
\hline \multirow[t]{6}{*}{ Current work status } & Employed full time & $327(30)$ \\
\hline & Self employed & $108(10)$ \\
\hline & Not in the labour force & $330(30)$ \\
\hline & Employed part time & $241(22)$ \\
\hline & Unemployed & $60(6)$ \\
\hline & Not reported & $26(2)$ \\
\hline \multirow[t]{8}{*}{ Current age (years) } & $15-19$ & $23(2)$ \\
\hline & $20-29$ & $162(15)$ \\
\hline & $30-39$ & $184(17)$ \\
\hline & $40-49$ & $187(17)$ \\
\hline & $50-59$ & $208(19)$ \\
\hline & $60-69$ & $177(16)$ \\
\hline & Over 70 & $142(13)$ \\
\hline & Not reported & $9(1)$ \\
\hline
\end{tabular}

. $\%$ of total respondents

of customers, arthritis by $20 \%$, high cholesterol levels by $16 \%$, asthma by $11.5 \%$ and diabetes by $5 \%$.

Age comparisons reveal a significantly greater proportion of customers aged 60 years or older reported having hypertension ( $50 \%$ vs $13 \%$; p < 0.0001), arthritis (48\% vs $9 \%$; p < 0.0001), hyperlipidaemia (30\% vs $10 \%$; $\mathrm{p}<0.0001)$ or diabetes $(11 \%$ vs $3 \%$; $\mathrm{p}<0.0001)$ compared with younger customers. No difference in frequency of asthma was found.

\section{Medication use}

Of the total sample, $61 \%$ reported using prescription medicines on a daily basis with $37 \%$ using one medicine, $36 \%$ using two to three medicines, $16 \%$ using four to five medicines and 9\% using more than five medicines daily. A significantly higher proportion of men reported using prescription medicines daily than women (25\% vs. $16 \% ; \mathrm{p}=0.0009$ ) and significantly higher proportion of people aged 60 years or older took prescription medication daily compared to younger people ( $87 \%$ vs. $48 \%$; $\mathrm{p}<0.0001)$.
CMs had been used by $72 \%$ of pharmacy customers ( $\mathrm{n}=787$ ) in the previous 12 months with significantly more women having used CMs than men (76\% vs. $58 \%$; $\mathrm{p}<0.0001)$. There was no significant difference in usage between younger customers and those aged 60 years or older (72\% vs 69\%). Of the people using CMs, $43 \%$ were also taking prescription medicines on a daily basis and $72 \%$ rated their CMs as 'very effective' or 'effective enough'.

The ten most popular CMs taken by pharmacy customers are listed in Table 2.

Age comparisons revealed a greater proportion of people over 60 years had been taking glucosamine (33\% vs. $16 \% ; \mathrm{p}<0.0001)$ or fish oil supplements ( $41 \%$ vs. $32 \%$; $\mathrm{p}=0.005)$ in the previous 12 months compared to younger people whereas significantly fewer in the older age category were using multivitamins ( $41 \%$ vs $22 \%$; p < $0.0001)$, vitamin $\mathrm{C}$ supplements $(25 \%$ vs $15 \%$; $\mathrm{p}=$ $0.0002)$, probiotics $(15 \%$ vs $6 \%$; $\mathrm{p}<0.0001)$ or echinacea (11\% vs $4 \%$; $\mathrm{p}=0.0002)$.

Respondents were asked who had recommended CMs to them, with most people reporting they had self prescribed (Table 3).

Pharmacists were not the main sources of information for pharmacy customers to learn about CMs. Friends and family, medical doctors, the media and naturopaths/ herbalists were more often referred to for information (Figure 1).

\section{Consulting practitioners}

Most (93\%) participants had seen a medical practitioner within the previous 12 months. Far fewer (39\%) participants had seen a CM practitioner in the last 12 months. Of those who had, 38\% saw a massage therapist, 33\% a naturopath, $31 \%$ a chiropractor, $16 \%$ an acupuncturist, $12 \%$ an osteopath, $9 \%$ a Chinese medicine practitioner, $4 \%$ a herbalist and 3\% a homeopath. Gender and age differences were identified with significantly more women having consulted a CM practitioner than men (43\% vs. $27 \% ; \mathrm{p}<0.0001)$ and a significantly greater proportion of younger customers consulting CM practitioners than those aged 60 years and older (45\% vs $25 \%$; $\mathrm{p}<0.0001)$.

\section{Customer expectations of pharmacy practice}

Attitudinal questions were asked of the total sample (CMs users and non-users) about pharmacy practice. The overwhelming majority (92\%) indicated that pharmacists should provide safety information about CMs and $90 \%$ thought they should routinely check whether CMs interact with prescription medicines. Additionally, $87 \%$ thought pharmacists should recommend CMs if they are effective and $78 \%$ thought pharmacists should record CMs taken by customers in their medication 
Table 2 CMs used by pharmacy customers in the previous 12 months

\begin{tabular}{lr}
\hline List of Top 10 CMs taken & N (\%) \\
\hline Multivitamins & $392(49)$ \\
Fish oil supplements & $379(47)$ \\
Vitamin C & $244(31)$ \\
Glucosamine & $234(29)$ \\
Vitamin B complex & $197(25)$ \\
Probiotics & $134(17)$ \\
Echinacea & $94(12)$ \\
Coenzyme Q10 & $57(7)$ \\
Ginkgo biloba & $41(5)$ \\
St Johns wort & $37(5)$ \\
Total customers responding & $\mathbf{8 0 1}$ \\
\hline
\end{tabular}

*\% of total respondents taking CMs

profile. Furthermore, 58\% thought pharmacies which stock CMs should also employ a CM practitioner. In regards to CMs specifically, $87 \%$ of customers thought effective CMs should have a 'tick of approval' from a recognised government body with $\mathrm{CM}$ expertise and $82 \%$ wanted more detailed product information similar to prescription medicine, for all CMs.

Pharmacy customers using CMs were asked more specific attitudinal questions relating to pharmacy practice. (Table 4).

\section{Discussion}

The primary aims of this project were to investigate the use, perceptions and attitudes of pharmacy customers to CMs and explore their expectations of pharmacists. CMs are popular amongst pharmacy customers with nearly 3 out of 4 reporting use of a CM product within the previous 12 months. Nutritional supplements feature most prominently, in particular multivitamins, fish oils, vitamin $\mathrm{C}$, vitamin $\mathrm{B}$ complex and probiotics. Herbal medicines were less commonly used than nutritional supplements and of these, echinacea, ginkgo, St Johns wort and valerian were most popular. This pattern of use (popularity of vitamin $\mathrm{C}$, multivitamins and fish oil

Table 3 Recommendation of CMs to pharmacy customers

\begin{tabular}{lr}
\hline Recommendation by: & Number (\%)* \\
\hline Myself & $335(42)$ \\
Medical doctor & $255(32)$ \\
Family/friends & $162(20)$ \\
Naturopath/herbalist & $160(20)$ \\
Pharmacy assistant & $100(13)$ \\
Health food store staff & $50(7)$ \\
Pharmacist & $81(10)$ \\
Other & $48(6)$ \\
Total responses & $\mathbf{8 0 1}$ \\
\hline
\end{tabular}

*\% of total respondents answering question supplements) is consistent with that reported in other Australian studies [16,17].

This study further establishes that CMs remain popular in the older age group although the pattern of use shifts with advancing age. The higher use of glucosamine or fish oil supplements in people aged 60 years or older is not surprising given the increased prevalence of hypertension, osteoarthritis and hyperlipidemia in this group and the established role of fish oils in cardiovascular disease [18] and potential benefits of glucosamine in osteoarthritis [19].

\section{Pharmacy customers want more from pharmacists}

Market research, and more recently health services and social science research, has adopted the concept of the 'new consumer' to describe customers or patients who are becoming more demanding $[20,21]$. They tend to be information strong (well-informed) and information seeking (inquisitive); ask critical questions; show a desire to initiate dialogue; seek counselling and in general no longer blindly accept the authority of health care providers.

Given the consumer-driven development towards holistic and integrative healthcare [22] some of the findings of this study are not surprising; for example, consumers acceptance of CM integration into pharmacy and their expectation for more interaction with pharmacists in this regard. Nearly all customers expect pharmacists to be knowledgeable about CMs and recommend CMs which are effective, to provide safety information, screen for drug-CM interactions and record patients' use of CMs in their medication profile. A small Canadian study also found customers want pharmacists to be knowledgeable about CMs and take on an advisory role to help them identify and assess information about CMs, and in particular, for them to provide guidance about safety issues [23].

Whilst customers want more engagement with pharmacists regarding CM issues, some customers currently feel that pharmacists are ill-equipped to counsel them about CMs and many do not refer to pharmacists as an information source. This correlates with pharmacists' own discomfort dealing with CM queries and feeling insufficiently informed about CMs [24-26]. It is possible that customer's interest in having access to a natural medicine practitioner within the pharmacy premises is a consequence of their current dissatisfaction with pharmacy practice, however this remains to be further investigated.

\section{Reducing clinical risk with CMs}

CMs, like all medicines, have the potential to cause adverse reactions. Reference texts and herbal pharmacopoeias give detailed information about adverse effects associated with 


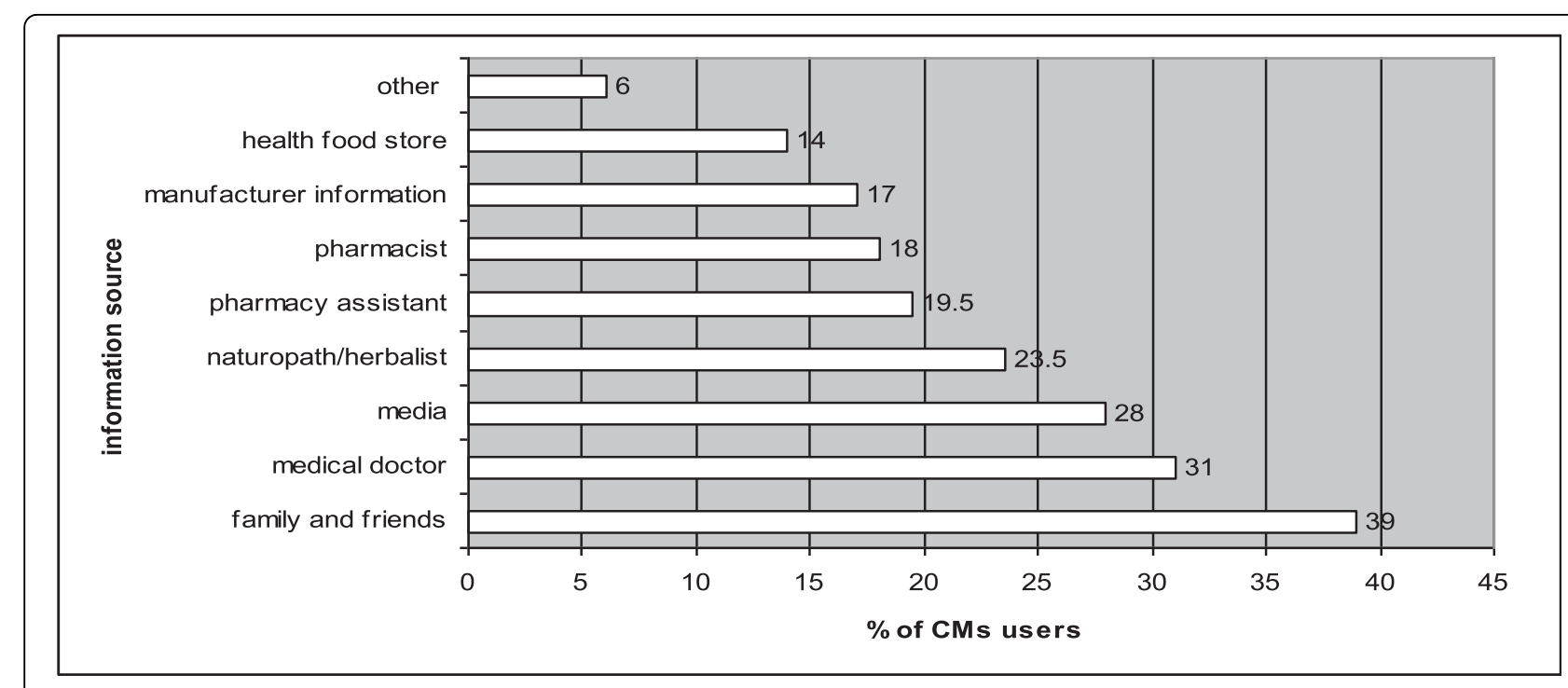

Figure 1. Sources of complementary medicines information used by pharmacy customers taking complementary products

Figure 1 Sources of $\mathrm{CM}$ information used by pharmacy customers $(\mathrm{N}=787)$.

Table 4 Pharmacy customers using CMs: attitudes to the pharmacists role in provision of CMs

\begin{tabular}{|c|c|c|c|c|c|}
\hline & \multicolumn{5}{|c|}{ Responses } \\
\hline & $\begin{array}{r}\text { Strongly } \\
\text { agree }\end{array}$ & Agree & $\begin{array}{r}\text { Neither agree or } \\
\text { disagree }\end{array}$ & Disagree & $\begin{array}{r}\text { Strong } \\
\text { disagree }\end{array}$ \\
\hline & $\mathrm{N}(\%)^{*}$ & $\mathrm{~N}(\%)$ & $\mathrm{N}(\%)$ & $\mathrm{N}(\%)$ & $\mathrm{N}(\%)$ \\
\hline My pharmacist is fully aware of any CMs I use & $79(11)$ & $164(22)$ & $193(26)$ & $192(25)$ & $120(16)$ \\
\hline I feel comfortable telling my pharmacist about my use of CMs & $165(22)$ & $372(50)$ & $140(19)$ & $46(6)$ & $19(3)$ \\
\hline It is important for pharmacists to be aware of the CMs people use & $290(39)$ & $337(46)$ & $91(12)$ & $21(3)$ & $3(0)$ \\
\hline My pharmacist encourages questions about CMs & $88(12)$ & $201(27)$ & $295(40)$ & $112(15)$ & $37(5)$ \\
\hline My pharmacist provides useful information about CMs & $103(14)$ & $250(34)$ & $261(36)$ & $91(12)$ & $27(4)$ \\
\hline $\begin{array}{l}\text { I think it is important for a natural medicine practitioner to be located in } \\
\text { a pharmacy where they sell CMs }\end{array}$ & $179(24)$ & $300(41)$ & $185(25)$ & $63(9)$ & $11(1)$ \\
\hline I trust my pharmacists' advice about CMs & $156(21)$ & $348(47)$ & $160(22)$ & $57(8)$ & $17(2)$ \\
\hline It is important for pharmacists to be knowledgeable about CMs & $299(41)$ & $383(52)$ & $44(6)$ & $10(1)$ & $2(0)$ \\
\hline Pharmacy assistants give me more advice about CMs than my pharmacist & $61(8)$ & $204(28)$ & $332(45)$ & $111(15)$ & $26(4)$ \\
\hline My pharmacist does not give me information about CMs & $40(5)$ & $145(20)^{\prime}$ & 281 (39) & 197 (27) & $66(9)$ \\
\hline
\end{tabular}

CMs and pharmacovigilance systems collect thousands of adverse reaction reports each year [27-29]. Unlike prescription medicines, CMs are often taken on the advice of family, friends or self determination and, as was observed in this study, are sometimes used in combination with pharmaceutical drugs.

Patient counselling can improve patient safety however in order for this to take place, customers that are interested in or currently using CMs must be willing to engage in discussion about these treatments with healthcare providers who in turn, must have sufficient interest and knowledge to provide an informed opinion about their safe and appropriate use.
It is often reported that people using CMs do not routinely disclose use to their medical practitioner. According to a review of 12 studies, the rate of non-disclosure of those using CM is as high as $77 \%$ in some studies [30]. The main reasons patients provide for not disclosing use to their medical practitioners are concerns about a negative response by the practitioners, the belief that the practitioner does not need to know about their CM use, and the fact that the practitioner does not ask. Pharmacy customers in this study did not display the same reticence about discussing CMs with pharmacists and the majority think it is important for pharmacists to 
be aware of the CMs being taken. This presents pharmacists with an opportunity to step up and take on a greater advisory role which would be welcomed by customers and improve patient safety.

Like all studies, this one has limitations which influence the generalisability of the findings. Self-administered surveys conducted in English are more likely to appeal to people with an interest in the topic being investigated and will limit participation to those people with stronger opinions about the issues being investigated and those that read and write English. Limitations also include the validity and reliability of self reported data. Whilst efforts were taken to recruit participants from different geographical locations at different times of the week in different types of pharmacies, it is possible that the customers participating in the study do not fully represent all pharmacy customers. Nevertheless the comparability of some of the data to other published reports of $\mathrm{CM}$ use by the Australian general public suggests that this is not a significant factor.

\section{Conclusion}

Most pharmacy customers have used or are using CMs and expect pharmacist to provide advice about CMs as part of pharmacy practice. Older customers (over 60 years) are also using CMs and for some products, their use is greater than for younger customers. Overall, people using CMs are satisfied with the results obtained from these products and see them as effective therapeutic agents. The challenge now remains for pharmacy practice to meet the needs of the community by up-skilling pharmacists to enable them to provide the guidance about CMs that customers seek.

\section{Additional material}

Additional file 1: Appendix. Customer CAM Survey

\begin{abstract}
Acknowledgements
This work was supported with the financial assistance of the Australian Government Department of Health and Ageing as part of the fourth community pharmacy agreement through the Fourth Community Pharmacy Agreement Grants Program managed by the Pharmacy Guild of Australia.
\end{abstract}

\begin{abstract}
Author details
${ }^{1}$ Cardiothoracic Surgical Research Unit, Department of Surgery, Monash University, Alfred Hospital, Melbourne, Australia. ${ }^{2}$ Department of Pharmacy, Alfred Hospital, Melbourne, Australia. ${ }^{3}$ Department of Pharmacy, Griffith University, Gold Coast, QLD, Australia. ${ }^{4}$ School of Biomedical Sciences, Charles Sturt University, Wagga Wagga, Australia. ${ }^{5}$ Faculty of Pharmacy and Pharmaceutical Sciences, Monash University, Parkville, Australia. ${ }^{6}$ Department of Epidemiology and Preventive Medicine School Public Health \& Preventive Medicine, Monash University Alfred Hospital, Melbourne, Australia.
\end{abstract}

\section{Authors' contributions}

LB conceived of the study, was project manager, co-ordinated data collection and chief author of this paper. ET and JW contributed to study design, co-ordinated data collection at their sites, MB was chiefly responsible for statistical analysis, OS, SP and MD aided in study design and all aided in results interpretation and have read and approved the final manuscript.

\section{Competing interests}

Authors of this manuscript have the following to disclose concerning possible financial or personal relationships with commercial entities that may have a direct or indirect interest in the subject matter of this presentation: Nothing to disclose for all authors.

Received: 17 March 2010 Accepted: 20 July 2010

Published: 20 July 2010

\section{References}

1. Eisenberg DM, Davis RB, Ettner SL, Appel S, Wilkey S, Van RM, et al: Trends in alternative medicine use in the United States, 1990-1997: results of a follow-up national survey. JAMA 1998, 280(18):1569-1575.

2. Xue CC, Zhang AL, Lin V, Da CC, Story DF: Complementary and alternative medicine use in Australia: a national population-based survey. J Altern Complement Med 2007, 13(6):643-650.

3. Gavin JA, Boon H: CAM in Canada: places, practices, research. Complement Ther Clin Pract 2005, 11(1):21-27.

4. McFarland B, Bigelow D, Zani B, Newsom J, Kaplan M: Complementary and alternative medicine use in Canada and the United States. Am J Public Health 2002, 92(10):1616-1618.

5. Zollman $C$, Vickers $A: A B C$ of complementary medicine. Users and practitioners of complementary medicine. BMJ 1999, 319(7213):836-838.

6. Kristoffersen S, Atkin P, Shenfield G: Use of Alternative Medicines on Sydney's North Shore. The Australian Journal of Hospital Pharmacy 1997, 27(5):367-372, Ref Type: Abstract.

7. MacLennan AH, Myers SP, Taylor AW: The continuing use of complementary and alternative medicine in South Australia: costs and beliefs in 2004. Med J Aust 2006, 184(1):27-31.

8. Australian Bureau of Statistics: 4102.0 Australian Social Trends. Australian Bureau of Statistics 2008, 13-7-0009. Ref Type: Report.

9. Tiralongo $\mathrm{E}$, Wallis $\mathrm{M}$ : Integrating complementary and alternative medicine education into the pharmacy curriculum. Am J Pharm Educ 2008, 72(4):74.

10. Tiralongo $E$, Wallis M: Attitudes and perceptions of Australian pharmacy students towards Complementary and Alternative Medicine - a pilot study. BMC Complement Altern Med 2008, 8:2.

11. Semple SJ, Hotham E, Rao D, Martin K, Smith CA, Bloustien GF: Community pharmacists in Australia: barriers to information provision on complementary and alternative medicines. Pharm World Sci 2006, 28(6):366-373.

12. Naidu S, Wilkinson JM, Simpson MD: Attitudes of Australian pharmacists toward complementary and alternative medicines. Ann Pharmacother 2005, 39(9):1456-1461.

13. Wilkinson JM, Simpson MD: Complementary therapy use by nursing, pharmacy and biomedical science students. Nurs Health Sci 2001, 3(1):19-27.

14. Australian Government DoHaA: Quality Use of Mediicnes. [http://www. foodsecretariat.health.gov.au/internet/main/publishing.nsf/Content/nmpquality.htm], Dept Health and Ageing [2009 [cited 9 A.D. Nov. 5]; Available from.

15. MacLennan AH, Wilson DH, Taylor AW: The escalating cost and prevalence of alternative medicine. Prev Med 2002, 35(2):166-173.

16. Braun L: Complementary medicines in Hospitals - a focus on surgical patients. RMIT University, Melbourne, Australia 2007.

17. Brownie S, Rolfe M: Health characteristics of older Australian dietary supplement users compared to non-supplement users. Asia Pac J Clin Nutr 2004, 13(4):365-371.

18. Lavie CJ, Milani RV, Mehra MR, Ventura HO: Omega-3 polyunsaturated fatty acids and cardiovascular diseases. J Am Coll Cardiol 2009, 54(7):585-594.

19. Poolsup N, Suthisisang C, Channark P, Kittikulsuth W: Glucosamine longterm treatment and the progression of knee osteoarthritis: systematic review of randomized controlled trials. Ann Pharmacother 2005, 39(6):1080-1087.

20. Traulsen JM, Noerreslet M: The new consumer of medicine-the pharmacy technicians' perspective. Pharm World Sci 2004, 26(4):203-207. 
21. Kwan D, Boon HS, Hirschkorn $K$, Welsh S, Jurgens T, Eccott L, et al: Exploring consumer and pharmacist views on the professional role of the pharmacist with respect to natural health products: a study of focus groups. BMC Complement Altern Med 2008, 8:40.

22. Hirschkorn KA: Exclusive versus everyday forms of professional knowledge: legitimacy claims in conventional and alternative medicine. Sociol Health IIIn 2006, 28(5):533-557.

23. Kwan D, Boon HS, Hirschkorn K, Welsh S, Jurgens T, Eccott L, et al: Exploring consumer and pharmacist views on the professional role of the pharmacist with respect to natural health products: a study of focus groups. BMC Complement Altern Med 2008, 8:40.

24. Naidu S, Wilkinson JM, Simpson MD: Attitudes of Australian pharmacists toward complementary and alternative medicines. Ann Pharmacother 2005, 39(9):1456-1461.

25. Brown CM, Barner JC, Shah S: Community pharmacists' actions when patients use complementary and alternative therapies with medications. J Am Pharm Assoc (Wash DC) 2005, 45(1):41-47.

26. Chang ZG, Kennedy DT, Holdford DA, Small RE: Pharmacists' knowledge and attitudes toward herbal medicine. Annals of Pharmacotherapy 2000, 34(6):710-715.

27. Braun L, Cohen M: Herbs and natural Supplements - an evidence based guide. Sydney: Elsevier, 2 2007.

28. Barnes J: Quality, efficacy and safety of complementary medicines: fashions, facts and the future. Part I. Regulation and quality. $\mathrm{Br} J \mathrm{Clin}$ Pharmacol 2003, 55(3):226-233.

29. Elvin-Lewis M: Safety issues associated with herbal ingredients. Adv Food Nutr Res 2005, 50:219-313.

30. Robinson A, MCGrail MR: Disclosure of CAM use to medical practitioners: a review of qualitative and quantitative studies. Complement Ther Med 2004, 12(2-3):90-98.

\section{Pre-publication history}

The pre-publication history for this paper can be accessed here: http://www.biomedcentral.com/1472-6882/10/38/prepub

doi:10.1186/1472-6882-10-38

Cite this article as: Braun et al:: Perceptions, use and attitudes of pharmacy customers on complementary medicines and pharmacy practice. BMC Complementary and Alternative Medicine 2010 10:38.

\section{Submit your next manuscript to BioMed Central and take full advantage of:}

- Convenient online submission

- Thorough peer review

- No space constraints or color figure charges

- Immediate publication on acceptance

- Inclusion in PubMed, CAS, Scopus and Google Scholar

- Research which is freely available for redistribution

Submit your manuscript at www.biomedcentral.com/submit 